\title{
Aftermath of Lockdown Throughout COVID- 19 Pandemic on Air Quality of Jaipur Vs Some Other Cities
}

\section{Hanumant Singh Chouhan}

Department of Chemistry, S.M.C.C. Government College, Aburoad, Rajasthan, INDIA

Study Area: Jaipur, India

Coordinates: $26^{\circ} 55^{\prime} \mathrm{N} 75^{\circ} 49^{\prime} \mathrm{E}\left(26.92^{\circ} \mathrm{N} 75.82^{\circ} \mathrm{E}\right)$

Key words: NO2, Lockdown, Air Index Quality, Corona virus.

\section{Abstract}

On 22 March 2020, a complete lockdown in India to avoid the COVID-19 outbreak had first been declared, and the lockdown was extended for 21 days in the first process on 24 March 2020. Mostly during the complete lockout, several of the causes of low air quality in India were shut down. This article uses land and satellite measurements to examine $\mathrm{AQ}$, particulate matter-PM ${ }_{2.5}$, AQI (Air Quality Index), and troposphere Nitrogen Dioxide across India. When comparing the lockout duration in 2020 to a certain period in 2019, a marked decrease in $\mathrm{PM}_{2.5}$ and AQI (Air Quality Index) was witnessed over metro cities and a decreasing pattern in troposphere $\mathrm{NO}_{2}$ intensity. Over the complete lockout time, environmental quality increased greatly, providing valuable insights to city administrations while they formulate laws and policies to increase air quality.

practices in less contaminated areas. The Fig.-1 depicts the period of the numerous COVID-19 lockout processes in India.

Although the developmental damage caused by COVID-19 has been massive across the globe, necessitating wartime planning from every region of the globe, it has also served as good news for the climate. Inger Andersen, the head of the UN Climate Program, claims that these ecological shifts are just for the short term since the world atmosphere got a brief relief before manufacturing activity returned in February 2020. Recent reports have also shown that the controls imposed on commercial operations after the lockdown improved air quality (Franco et al., 2015). According to climate science, greenhouse gas concentrations may fall to amounts not seen since World War II. Air emissions were lower in highly developed cities situated in low-temperatureareas.

Lockdowns in numerous nations, including Germany, Spain, Italy, France, and China, culminated in the shutdown of transportation, power plants, and other sectors, resulting in significant reductions in Greenhouse gases in the atmosphere, $\mathrm{NO}_{2}, \mathrm{PM}_{2.5}, \mathrm{PM}_{10}$, and $\mathrm{CO}$ levels while concurrently spiking ozone layer, especially in Europe and major Chinese towns. The improvements in air quality across the Yangtze River Delta Region during COVID-19 lockdown show that decreased human interaction and industrial activities result in substantial reductions in $\mathrm{PM}_{2.5}$, Nitrogen Dioxide, and Sulphur Dioxide (Fuentes et al., 200o). And during COVID-19 lockdown time, the The lockdown, which was categorized into stages, was

*Corresponding Author:draburoad@gmail.com 


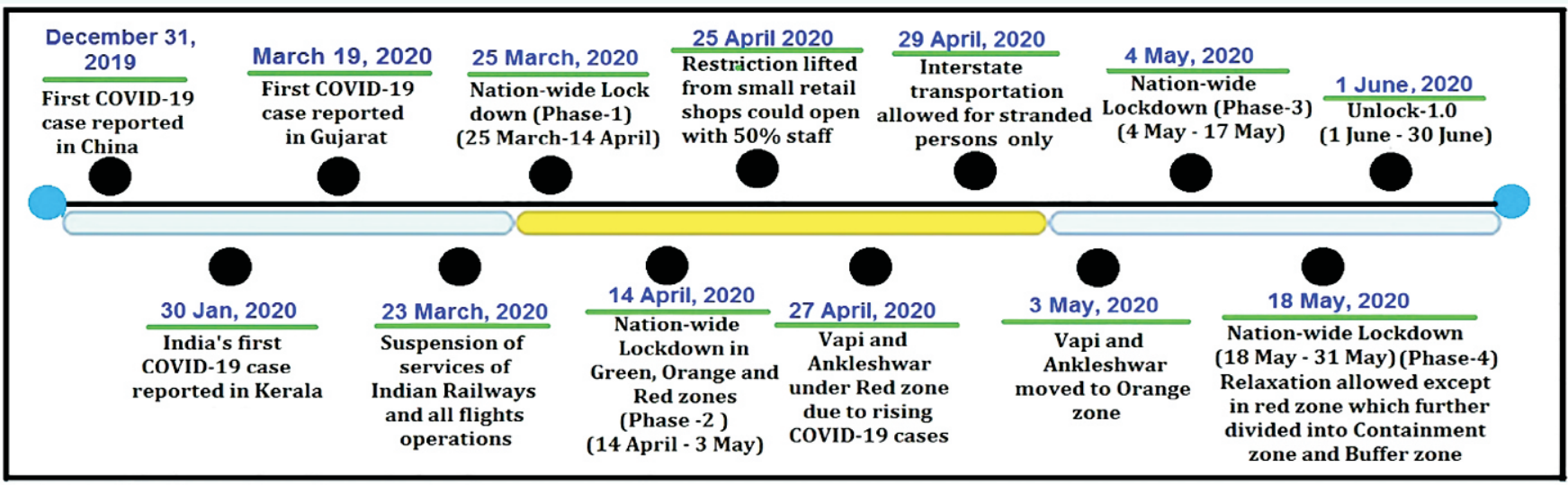

Figure 1: In developing areas, the COVID-19 lockout has a positive effect on air quality.

Hangzhou metropolis saw a considerable change in air quality, as illustrated by lower Fine Particulates, Nitrogen Oxide, Sulphur Dioxide, and CO levels. During the lockdown in the United States, lower Nitrogen Dioxide (49\%) and CO (37\%) levels were favourably associated with increased demographic growth. The effect of the steps on air quality in Rio de Janeiro, Brazil, was addressed by contrasting particulates, $\mathrm{CO}, \mathrm{NO}_{2}$, and ozone levels throughout the temporary lockdown with those in the same timeframe of 2019 and also with others in the weeks leading up to the disease spread.

The levels of the 3 key major air contaminants in So Paulo and Rio de Janeiro, the 2 most populous areas, demonstrated a favourable impact on the rates of the 3 main major air contaminants, with the carbon monoxide levels seeing the most substantial decreases, which were attributed to light-duty automobile pollution. Changes in the levels of certain air contaminants as a result of a series of fast and tight countermeasures restricting community movement and banning almost all avoidable behaviours were assessed in Salé (North-Western Morocco). "Barcelona's air quality was assessed using a remote sensing dataset given by ESA's Troposphere monitoring instrument and specific air quality monitoring data to determine variations in air quality throughout the lockdown and one month prior to the lockdown." Lockdown resulted in declines of $31 \%$ and $51 \%$ in Nitrogen dioxide and $\mathrm{PM}_{2.5}$, respectively (Fuentes et al., 2020). The National Aeronautics and Space Administration detected a decrease of $10-30 \%$ in $\mathrm{NO}_{2}$ in eastern and central China during early 2020 using the TROPOMI sensor. In the California basin region, there was a $27 \%$ decrease in nitrogen oxides levels compared to the previous 5 years, as well as non-uniform trends in $\mathrm{O}_{3}$ levels during the lockout. In Hangzhou, China, black carbon mitigation has been reported as a result of the lockout put on anthropogenic activities. PM1o and PM2.5 concentrations were reduced by $43 \%$ and $31 \%$, respectively, while $\mathrm{O}_{3}$ concentrations increased by $17 \%$ during the lockout duration and compared to previous 4-year levels in various parts of India.
$\mathrm{NO}_{2}, \mathrm{SO}_{2}$, and $\mathrm{PMio}$ are natural pollution contaminants in towns and industrial regions, and they cause cardiovascular including respiratory disorders. Vehicle waste, road salt, and metal manufacturing plants are the major origins of these contaminants. The bulk of the beneficial effects were found in 31 Chinese regional metropolitan areas where $\mathrm{No}_{2}$ levels (Gautam, 2020) were reduced. The constant deterioration of AQ in several Indian major areas like "New Delhi, Mumbai, Kolkata, Chennai", which often surpass WHO and Central Pollution Control Board of India norms, has consolidated their daily inclusion in the index of the world's top 20 contaminated areas. In 2019, the Ministry of the Environment, Forestry, and Climate Change announced a five-year action plan under the National Clean Air Programme to reduce particulate matter concentrations by $30 \%$ throughout the country. In 88 Indian cities, the nationwide mandatory lockout has culminated in a drastic reduction in air quality.

\section{Methodology:}

Study region: Jaipur is the capital city of state Rajasthan, India and as such, it hosts a plethora of economic as well as bureaucratic events during the year. Jaipur, which is also regarded as the Pink City, is one of India's most famous tourist attractions. It is also a component of the tourism triangle, which involves the country's capital, Delhi, the Taj Mahal city of Agra, and Jaipur. As a result, Jaipur sees a variety of incoming and outgoing visitors during the year. The atmosphere in the area is semiarid.

Establishing monitoring centres in different parts of Jaipur was part of the technique. The study's key evidence was centred on measurements produced in 1996-97 for air pollutants attributed to Sulphur Dioxide, Nitrogen Dioxide, Carbon Monoxide, and pendant particulate matter, as well as noise pollution, and the most recent data collections, i.e., during the COVID-19 event, were from publicly accessible web-based platforms. The sampling absorbance was determined using specttrophotometry (Gautam \& Hens, 2020; Guo et al., 2017). The analysis divided Jaipur into 4 groups: industrial (4 areas), commercial (28 areas), 

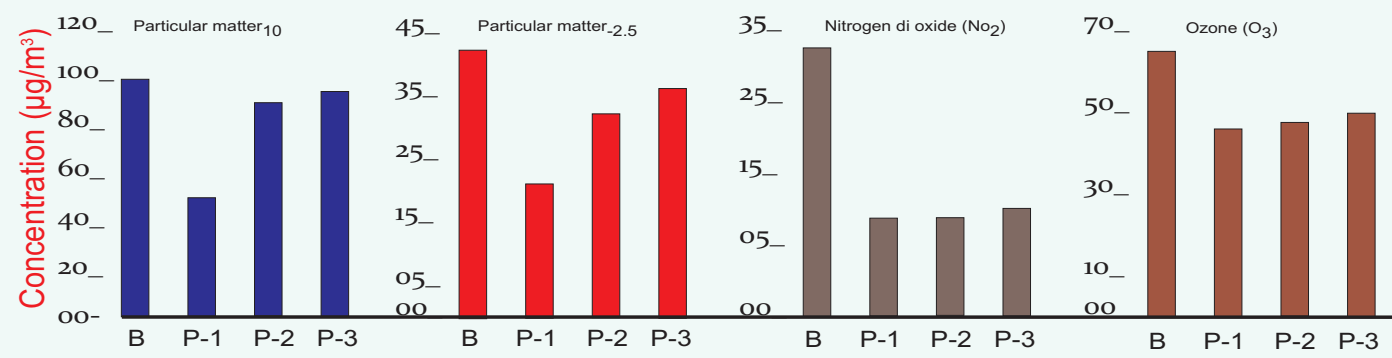

16_ Sulper di Oxide $\left(\mathrm{So}_{2}\right)$

Figur-2: During lockdown period at Jaipur, the analysed values

residential (13 regions), and vulnerable areas (13 areas) (4 nos.). In 1997, the highest concentrations of sulphur dioxide were observed in Gopalpura and Ramgunj, which can be due to the high volume of congestion in these regions. The sound levels are depicted in a survey conducted in 1997, which shown the maximum noise levels in business regions. Owing to vast amounts of unregulated automobile congestion and their location in the heart of Jaipur, the affected areas often have elevated noise levels (Gua et al., 2019). Today, observations, coupled with air quality index values, are made accessible for review on webbased websites through technical advancements. "The Rajasthan State Pollution Control Board operates stations in Adarsh Nagar, the Police Commissionerate, and Shastri Nagar in Jaipur $\mathrm{PM}_{2.5}, \mathrm{PM}_{10}, \mathrm{NO}_{2}, \mathrm{Nh}_{3}, \mathrm{SO}_{2}, \mathrm{CO}$, and Ozone. The majority of the experiments used APM 411 or derivatives of APM 411 respirable dust samplers. Using Decibel meters, Johari et al. (2019) surveyed fifteen places in Jaipur city in 2019 to research noise levels and methods to reduce their effects."

The elevated amount of cars in the region increases motor vehicles' exposure to total emissions, which is one of the primary causes of traffic noise. Nevertheless, owing to stagnant anthropogenic operations, the COVID-19 first lockdown era had the minimum noise pollution. It has been investigated air pollution at 12 locations in Jaipur, including housing, agricultural, and commercial areas. According to the Air Quality Index, the data indicate mainly higher to medium levels of air contamination. Cartosat-1 orthoimage is used to visualise the study field. Throughout pre-COVID-19 field research, including a visit to Jaipur for analyses performed utilising geospatial technologies, the atmospheric circumstances of the town were examined.

On the 15th of May, the AQI in Jaipur was 92 at 9:00 a.m. on the website, respectable. The Air Quality Index in Delhi was mild on the same day, on the 15th of May. The emission standards have decreased further following the intense rainfall on August 15th in Jaipur, which resulted in $176 \mathrm{~mm}$ of rain in 24 hours (Monserrate et al., 2020; He et al., 2020). Mostly during the third lock-down, also known as the unlocking process, the National Air Quality Index shows "Good" conditions much of the period, even during afternoon and evening peak traffic, on straight months until August 24, 2020, whereby several operations have revived, but on a smaller level or severity.
The Chief Minister of Rajasthan placed a nationwide lockout in the Rajasthan from March 22nd to March 31st, 2020, in an effort to fight the alarming outbreak of the COVID-19 pandemic. AQ was improved in many urban centres throughout the area as a consequence of tight traffic limits and the shutdown of non-essential operations, particularly those in air polluting industries. Transportation, factories, power stations, building works, biomass And waste burning, ground dust re-suspension, and housing practices are the main contributors to air emissions. "The Rajasthan State Pollution Control Board monitors the quality of the state via its system of Continuous Ambient Air Quality Monitoring Stations in Jaipur, Alwar, Ajmer, Bhiwadi. Jodhpur, Kota, Pali, and Udaipur." To assess the effect of the lockout on the province's AI, a brief review of data obtained from these stations was conducted on the AQI and popular contaminants such as $\mathrm{PM}_{10}, \mathrm{PM}_{2.5}$, and $\mathrm{NO}_{2}$. Pre-lockdown data was collected from 15.03.2020 to 21.03.2020, and postlockdown data was collected from 22.03.2020 to 7.04.2020. The following are the report's main findings: The province's air quality index has greatly improved as a result of the lockout (www.eea.europa.eu/highlights/air-pollution-goes-down-as). The Air Quality Index was improved to "Acceptable" at all stations, up from "Poor" to "Acceptable" previously. The decreasing trend in AQI at these "Continuous Ambient Air Quality Monitoring Stations" was varied from 21\% (Shashtri Nagar, Jaipur) to 68\% (Shashtri Nagar, Jaipur) (Bhiwadi- RIICO Ind. Area III). Due to the closing of manufacturing operations and the resulting decrease in road traffic, including re-suspension of street dirt, Bhiwadi shown the greatest change in Air Quality Index. In terms of actual contaminants, Bhiwadi shown a 70\% decrease in $\mathrm{PM}_{10}, \mathrm{PM}_{2.5}$, and $\mathrm{NO}_{2}$ concentrations as a result of the lockdown. Other regions where vehicular emissions and street dust re-suspension are the primary sources of air contamination shown substantial reductions in large contaminants varying from $27 \%$ to $73 \%$ (Nie et al., 2020). $\mathrm{PM}_{2.5}$ levels were lower earlier in the lockout, which may be attributed to the more efficient implementation of the lockdown and an increase in air levels in certain areas, leading to greater contaminant scattering.

Aftermath of Lockdown on AQ of Other Cities: Before and after the lockout, the final nation averages for 
$\mathrm{PM}_{10}$ measured using approximated estimates were 116 $\mathrm{g} / \mathrm{m}^{3}$ and $70 \mathrm{~g} / \mathrm{m}^{3}$, respectively. With a po.05 significance, statistical methods using a t-test revealed a substantial change in PMio rates before and during the lockout. $\mathrm{PM}_{10}$ values before and after lockdown, with $\mathrm{PM}_{10}$ levels improving during the lockdown. Before and after the lockout, the total nation averages measured by using the approximated figure for $\mathrm{PM}_{2.5}$ were $56 \mathrm{~g} / 3$ and $31 \mathrm{~g} / 3$, respectively. With a po.05 significance, statistical methods using a t-test revealed a substantial change in $\mathrm{PM}_{2.5}$ levels before and during lockout (Shi et al., 2020). $\mathrm{PM}_{2.5}$ values before and after lockdown as seen in Fig.-3 with $\mathrm{PM}_{2.5}$ values improving after lockdown. Many states in the south had low $\mathrm{PM}_{10}$ and $\mathrm{PM}_{2.5}$ rates pre and post-lockout relative to other Indian regions.

Nevertheless, by comparing the increase in AQ after a lockdown in absolute numbers, the states in the south reported a smaller increase than the other regions. Although this change was less in actual terms, the air quality in the southern states improved overall. WB had the maximum enhancement in AQ in terms of the percentage change in air quality measured using real $\mathrm{PM}_{2.5}$ and $\mathrm{PM}_{10}$ results. In terms of $\mathrm{PM}_{2.5}$ standards, Orissa had the smallest increase in air quality (10\%). The percentage reduction of $\mathrm{PM}_{2.5}$ in Haryana, Uttar Pradesh, and Bihar was greater than the substantial decrease of $\mathrm{PM}_{10}$. In North-East states, including Arunachal Pradesh and Meghalaya, the $\mathrm{PM}_{2.5} / \mathrm{PM}_{10}$ ratio was greater than 0.5 , indicating that $\mathrm{PM}_{2.5}$ made up a significant portion of $\mathrm{PM}_{10}$ (Li et al., 2020). Since the NE regions are less advanced and sparsely inhabited, this finding suggests that $\mathrm{PM}_{2.5}$ is transported long distances from other locations. The overall decrease proportions for $\mathrm{PM}_{10} 44 \%$ and $\mathrm{PM}_{2.5} 51 \%$ around the nation were slightly diverse $(<\mathrm{p} 0.05)$, with $\mathrm{PM}_{2.5}$ shown a better decrease.

Pre and post the lockout, the final nation estimates that use the approximated amount for Nitrogen dioxide was $30.45 \mathrm{~g} / \mathrm{m}^{3}$ and $14.64 \mathrm{~g} / \mathrm{m}^{3}$, respectively. There was a substantial change in Nitrogen dioxide amounts pre and post-lockout, according to statistical analyses using a t-test. Levels of nitrogen oxides before and during the lockout, as well as increases in nitrogen oxides levels during the lockdown are visible. Under the lockout, the overall volume of nitrogen oxide in the atmosphere was cut in half. Automobiles are the main cause of nitrogen dioxide in the environment, and amounts of nitrogen oxide are expected to plummet. On March 24th, 2020, a 60\% drop in congestion was recorded shortly after the introduction of lockdown. Morning road traffic in Delhi was between 50 and $80 \%$ in 2019, but it has since been decreased to single only digits, varying from o to $6 \%$. "Likewise, traffic jams in Bombay were 60 to $80 \%$ during morning peak times in 2019, and it declined to $52-74 \%$ in the highly congested areas of Noida, Greater Noida, and Ghaziabad (52-74\%), Haryana
(74\%), Kanpur (54-66\%), Chennai (67\%), Udaipur (68\%), Kota (57\%), Jodhpur (55\%), Jaipur (66\%), (65\%)." Reductions were also seen in Delhi's major roads (50-75\%), MP's (6o-7o\%), and Bangalore's (6o-70\%) $(58-80 \%)$. The output of Nitrogen dioxide from diesel vehicles is greater than that of petrol vehicles. The fact that diesel vehicles account for the majority of licensed automobiles could have led to a higher $\mathrm{NO}_{2}$ reduction (Yuan et al., 2020). Compressed natural gas vehicles account for a large percentage of automobiles in Delhi. While compressed natural gas vehicles produce less contaminant than petrol and diesel automobiles in $\mathrm{PM}_{10}, \mathrm{PM}_{2.5}$, and Sulphur dioxide, studies show that Nitrogen oxide emissions are not significantly reduced.

Pre and post the lockdown, the final nation estimates using the approximated amount for Sulphur dioxide were 14 $\mathrm{g} / \mathrm{m}_{3}$ and $11 \mathrm{~g} / \mathrm{m}^{3}$, respectively. With such a significance, statistical methods using a t-test revealed a substantial variation in $\mathrm{SO}_{2}$ amounts pre and post lockout. $\mathrm{SO}_{2}$ values pre and post-lockdown and improvements in $\mathrm{SO}_{2}$ levels during lockdown are seen. The states in the south of Kerala and Tamil Nadu had the lowest Sulphur dioxide amounts during the lockdown time (Dantas et al., 2020). India is the world's biggest emitter of Sulphur dioxide, with 45 locations contributing to the nation's pollution. Coal-fired power plants are used in 43 of the 45 locations. While the coal mines in Talcher Coalfields, Orissa, are still operating, but at decreased capability, a 50\% decline in Sulphur dioxide was reported. In several manufacturing belts around the region, there was also a major decline in $\mathrm{SO}_{2}$. "For eg, Jahangirpuri in Delhi (70\%), Pusa in Delhi (50\%), GIDC in Ankleshwar in Gujarat (78\%), Phase-4 GIDC in Vatva in Gujarat (83\%), Industrial belt near Chhatrapati Shivaji International Airport in Mumbai (83\%), Mahape in Navi Mumbai (59\%), and RIICO Industrial Area III in Bhiwadi in Gujarat (72\%)."

Pre and post the lockdown, the final nation estimates using approximated figures for $\mathrm{O}_{3}$ were $35 \mathrm{~g} / \mathrm{m}^{3}$ and 37 $\mathrm{g} / \mathrm{m} 3$, respectively. The marginal rise is due to higher photochemical production as a result of the lower particulate matter level. With a p>0.05, statistical analyses



Figure 3: Effect of lockdown on AQ of various cities in India 


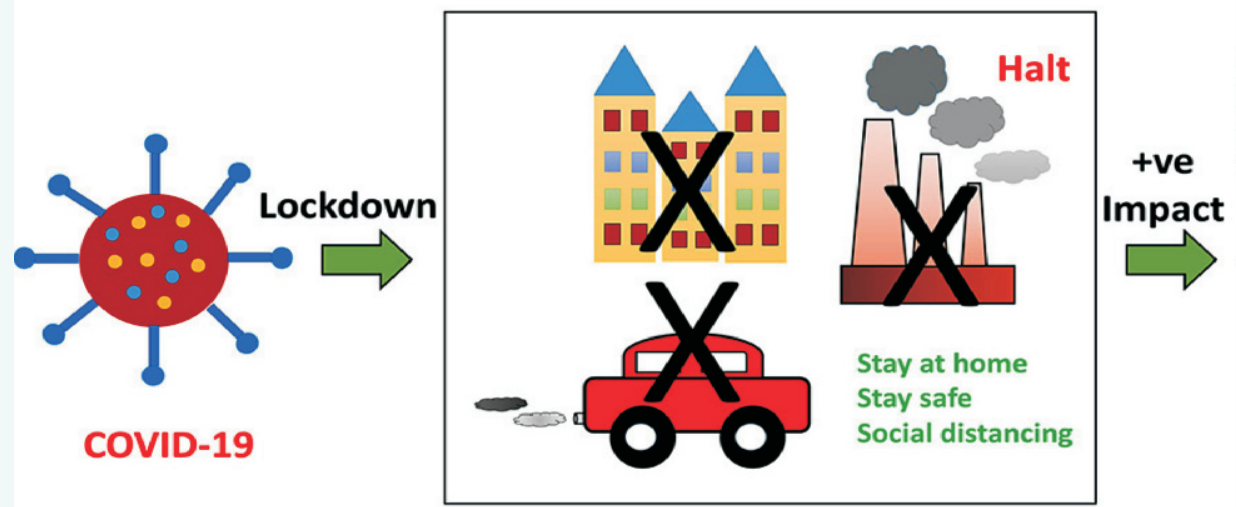

Figure-4: Improving air quality during lockdown using the t-test revealed no substantial change in $\mathrm{O}_{3}$ levels pre and post lockdown. The Fig.- 5 depicts $\mathrm{O}_{3}$ values pre and post lockdown, as well as $\mathrm{O}_{3}$ levels improving during the lockdown. Before the lockout, certain parts of Rajasthan and Madhya Pradesh had the maximum total $\mathrm{O}_{3}$ intensity (Siciliano et al., 2020). The $\mathrm{O}_{3}$ concentrations were found to be lower in the southern, western, and northeastern nations during the lockout. At the same period, $\mathrm{O}_{3}$ intensity rates in Madhya Pradesh, several regions of "Rajasthan, a few Northern states, and West Bengal" increased slightly. PMio levels were higher before the lockout time in the eastern areas and "northern states of Delhi, Uttaranchal, Haryana, and Uttar Pradesh". As seen in, the country's Air Quality Index levels have increased overall. West Bengal had the greatest growth in Air Quality Index $(61.89 \%)$, led by AP $(48.80 \%)$, and Meghalaya $(48.80 \%)(47.58 \%)$. Orissa saw the least amount of transition (3.55\%). Pre and pro the lockdown, the AQI in Orissa was 132.49 and 127.78, respectively (Otmani et al., 2020). Before the lockout, the Air Quality Index in the states in the south was below acceptable limits. Jaipur had the largest percentage decrease in Air Quality Index among the urban centres, led by "Kolkata, Mumbai, Pune, and New Delhi". The city with the smallest decrease was Chennai. The Air Quality Index values in "other major cities, such as Bangalore, Hyderabad, and Ahmedabad", were reduced by a
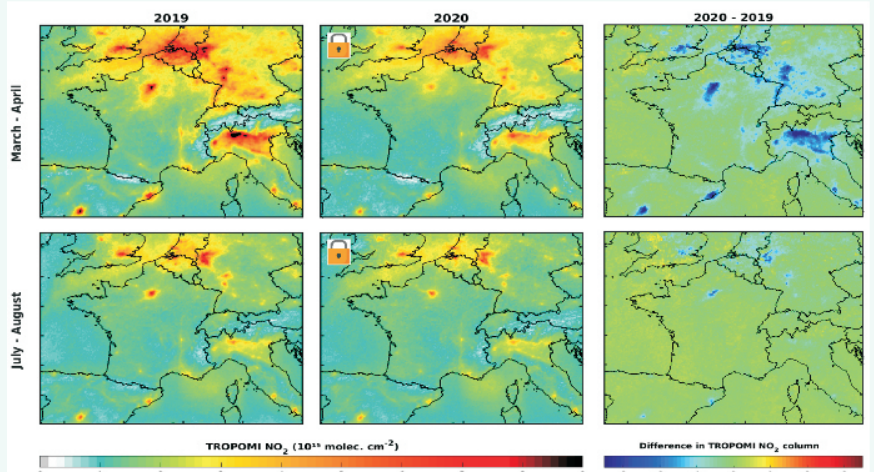

Figure 5: The proportional decrease in emissions in all 3 parts (roads, housing, and manufacturing) similar amount. While Chennai had the lowest Air Quality Index value before the lockdown, Jaipur had the cheapest quality after the lockdown. In addition, New Delhi had the maximum value both preand post-lockout.

The number of days that contaminant levels surpassed the allowable amounts were calculated by comparing approximated contaminant levels to NAAQS. Gaseous contaminants (Nitrogen oxides, $\mathrm{SO}_{2}$, and $\mathrm{O}_{3}$ ) were found to be below allowable limits both before and after the lockout. "There was no day when the state estimated value crossed the allowable parameters as recommended by CPCB in the context of $\mathrm{Pm}_{10}$ in West Bengal, Telangana, Meghalaya, Maharashtra, Kerala, Karnataka, Chandigarh, and Andhra Pradesh after the lockdown was implemented." As seen in Fig, the proportional decrease in emissions in all 3 parts (roads, housing, and manufacturing) was about $40 \%$ since the introduction of COVID-19 lockdown. "Mumbai, Delhi, Bangalore, Hyderabad, Ahmedabad, Chennai, Kolkata, Surat, Pune, and Jaipur are the most populous cities in India, according to census data from 2011." Except for Surat, all of these cities had data accessible (Tobías et al., 2020; Patel, 2020). As seen in Fig.-6, most towns saw a more than $50 \%$ drop in $\mathrm{PM}_{2.5}$ concentrations since the lockout began. The mean concentration levels for ambient air in all of the cities fell below the CРCB guidelines, and the regular average values remained below confines for about $95 \%$ of the time. In the case of $\mathrm{PM}_{10}$, similar findings were made. In all other cities apart from Delhi, where it only crossed the line, its mean application dropped within CPCB limits. In these towns, the concentration dropped by around $47 \%$, and the values stayed below the cap for $91 \%$ of the time. Even before the lockout, atmospheric air levels of Nitrogen dioxide and $\mathrm{SO}_{2}$ were below acceptable levels in both of these cities. The lockdown lowered Nitrogen oxide levels by $30.45 \mathrm{~g} / \mathrm{m}_{3}$ to $14.64 \mathrm{~g} / \mathrm{m}_{3}$ and $\mathrm{SO}_{2}$ levels by $14 \mathrm{~g} / \mathrm{m}^{3}$ to 11 $\mathrm{g} / \mathrm{m}^{3}$. On a few days ( $1 \%$ of the time), their values met the allowable limits $\left(8 \mathrm{og} / \mathrm{m}^{3}\right)$. Due to lockdown, ozone, on the other side, demonstrated a downward trend (Parker et al., 2020). The intensity of ozone rose in New Delhi, Kolkata, 
Chennai, and Hyderabad, increasing from 3.8 to $38.3 \%$. The connection evaluation method may be used to investigate the relationships between two contaminants. Densities that are highly clustered are representative of different origins for both contaminants.

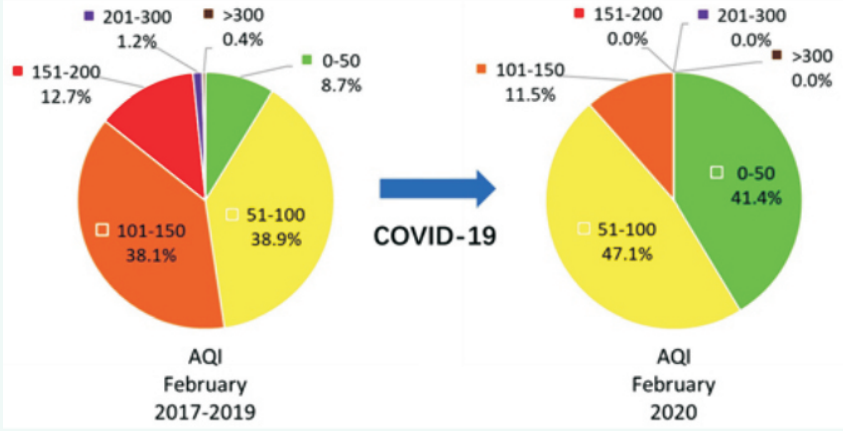

Figure-6: COVID-19 Effects, Air Quality Index, and Indicatory Air Pollutants

The $\mathrm{PM}_{10}-\mathrm{PM}_{2.5}$ couple is favourably associated with Pre (o.88) along with post (0.74) the lockout, indicating that both of these contaminants have a similar origin. The " $\mathrm{PM}_{10}-\mathrm{NO}_{2}$ and $\mathrm{PM}_{2.5}-\mathrm{NO}_{2}$ " pairs have large coefficients as well. $\mathrm{NO}_{2}$ understands this connection because automobiles are a common cause of particulate matter. The higher association between decreases in $\mathrm{PM}_{2.5}$ and Nitrogen oxide relative to their levels in ambient air pre and post-lockdown means that their decreases are mostly attributed to the elimination of diesel automobiles from the streets lockdown (Xu et al., 2020). The favourable association of " $\mathrm{PM}_{10}$ and $\mathrm{PM}_{2.5}$ with $\mathrm{O}_{3}$ " during the lockout time was a remarkable finding. This suggests that photochemical reactions, which often result in the production of $\mathrm{O}_{3}$, are a major origin of $\mathrm{PM}$ after the lockout. With most anthropogenic origins of main particulates depleted, secondary particulates produced by chemical processes between different contaminants account for a significant portion of the accessible particulate matter. " $\mathrm{PM}_{10} / \mathrm{O}_{3}$ and $\mathrm{PM}_{2.5} / \mathrm{O}_{3}$ " were either incommensurable or adversely associated prior to the lockout time. Both pre and post the lockout time, there was no meaningful association between $\mathrm{NO}_{3} / \mathrm{SO}_{2}, \mathrm{SO}_{2} / \mathrm{O}_{3}$, and $\mathrm{NO}_{2} / \mathrm{O}_{3}$, suggesting that these contaminant pairs come from separate origins.

A major variation of viewpoint was discovered after running two experiments on the answers received from rural and urban populations " $2(2, \mathrm{~N}=1750)=43.99$, p o.05". During the lockdown, urban responders noticed a greater change in air quality (64\% to $49 \%)$. The reported impact size was Cramer's $V=0.2$, meaning that the variation in vision has a modest impact factor (Sharma et al., 2020). This demonstrates that, despite substantial differences of opinion, citizens in both rural and urban areas expect air quality improvement.

A substantial variety of viewpoints was found when various forms of territory were considered, $2(2, \mathrm{~N}=1395)=$
18.987, p as seen in fig, close to road junctions $>$ Housing $>$ Close to hospital Because of the outbreak, proximity to hospitals was deemed a different group, with further traffic expected around hospitals. More than half of respondents in all towns thought air quality had improved: Delhi (100\%), Ahmedabad (85\%), Chennai (83\%), Mumbai (80\%), Bangalore (65\%), Jaipur (65\%), and Hyderabad (66\%) $(54 \%)$. To determine differences in opinion among India's various areas, a nonparametric test was used. With the exception of "Southern zonal council vs. Northern zonal council and Southern zonal council vs. Central zonal council", viewpoint on change was determined and compared on Likert scale across all areas in the region pvalue of 0.05. "Likewise, major variations in answers were seen between the North Eastern vs. Central and Western zonal councils, as well as the Northern vs. Central zonal councils, with a p-value of Street dust > Building activities > Factories $>$ Road side burning $>$ Burning of farm waste $>$ Power station. After the lockout, nevertheless, the order was changed to Domestic emissions $>$ Solid waste burnings $>$ Traffic $>$ None $>$ Industrial activities $>$ others." Other causes involved cracker fire, disinfectant chemical spraying, and smoking (Koken et al., 2003). As supplementary content, the perceptions of sources within various localities and zonal councils are presented. According to Google Pattern Analysis, words relating to air pollution is increasing from Oct to Dec in theyear 2019.

According to Google Statistical Analysis, the states of Delhi, Haryana, Uttar Pradesh, Punjab, Uttarakhand, as well as HP had the most queries. Every year from October to December, North and northwest India experience heavy air contamination as a result of stubble burning, which is exacerbated by weather conditions. Including a minor increase on March 22, 2020, the day the Janata curfew was enforced, the pattern that had deteriorated dramatically since once in the year emission incident sustained to decline throughout the lockdown era, though at a slower pace. This pattern may be viewed as a loss of media impact on the public's view of air quality.

\section{Comparison of AQ Pre and Post Lockdown:}

To deal with this urgent condition, the regional and federal governments took a number of measures. Following an isolation moratorium known as the "Janta Curfew," the Indian authorities enforced a full "lockdown from March 25 to April 14, 2020, for 21 days" which was said to be phase 1, which was later expanded to phases 2, 3 and 4 to prevent the outbreak from spreading more. This meant self-isolation, a major decrease in road and air transport, and a stop to a variety of other recreational sports, such as industrial, commercial, and building (Thorpe \& Harrison, 2020). As a result of the lockout, the ecosystem has experienced a very unusual favourable effect, particularly a dramatic change in $\mathrm{AQ}$ in different regions of the globe. This may be a huge relief since air contamination is a global health problem 
that causes a variety of illnesses such as "cardiovascular and respiratory infection, asthma, bronchitis, chronic obstructive pulmonary disorder", lung and cardiac stress, and a shorter life expectancy (LeTertre et al., 2002). The very first effect of the Nitrogen oxides lockout on AQ has been confirmed from Wuhan, China. Following that, other reports from China, New York, So Paulo, Barcelona, and other cities recorded significant reductions in " $\mathrm{PM}_{2.5}, \mathrm{PM}_{10}$, $\mathrm{NO}_{\mathrm{x}}$, and CO" throughout the lockout phase. "This has been researched in India's major cities, including Delhi, Mumbai, Hyderabad, Kolkata, and others.” These reports, though, just looked at the early trend, and it is still unclear what occurred since the lockout was removed. Also, the improvement in AQ caused by COVID-19 has been recorded to be available in various regions/locations and does not obey a common pattern. As a result, a local analysis is essential to assess the trend of improvements.

Moreover, various studies have been conducted after the epidemic began to explain the factors that influence SARC-CoV-2 spread, with a special focus on the relationship between the immune system, population size, and climatic conditions more. Air contamination is believed to trigger a variety of respiratory ailments; the greater the penetration, the greater the threat hypothesis. As a result, there has been a lot of curiosity on whether indoor air contaminants like $\mathrm{PM}_{2.5}, \mathrm{PM}_{10}, \mathrm{No}_{\mathrm{x}}$, and $\mathrm{CO}$ are linked to the COVID-19. Bad AQ has been related in some of the research to the seriousness of COVID-19 outcomes. Variations of temperature as well as moisture have also been linked to influenza and other respiratory diseases, including such "severe acute respiratory syndrome", among others (He et al., 2020). A few research sought to assess the function of climatological variables such as temperature humidity levels, dew point, air velocity, and rainfall in the distribution of COVID-19 based on this logic. Other variables, such as demographic size, resident "age profiles, and sex-ratios", have been attributed to this pandemic (Garaga et al., 2018). Nevertheless, the findings of these experiments are also debatable. Moreover, this subject is still in its early stages, and there is currently inadequate

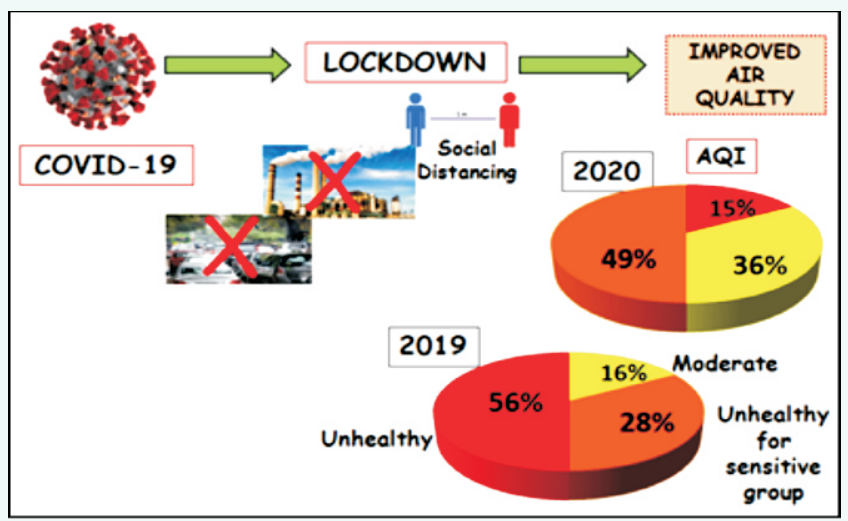

Figure-7: The trend of air quality improvements during covid 19 lock down. evidence. Furthermore, the distribution of COVID-19varies by area, based on the local climate and atmospheric circumstances and also government guidance, among other factors. As a result, more thorough and thorough research is needed in every area that considers these aspects to measure the outbreak accurately.

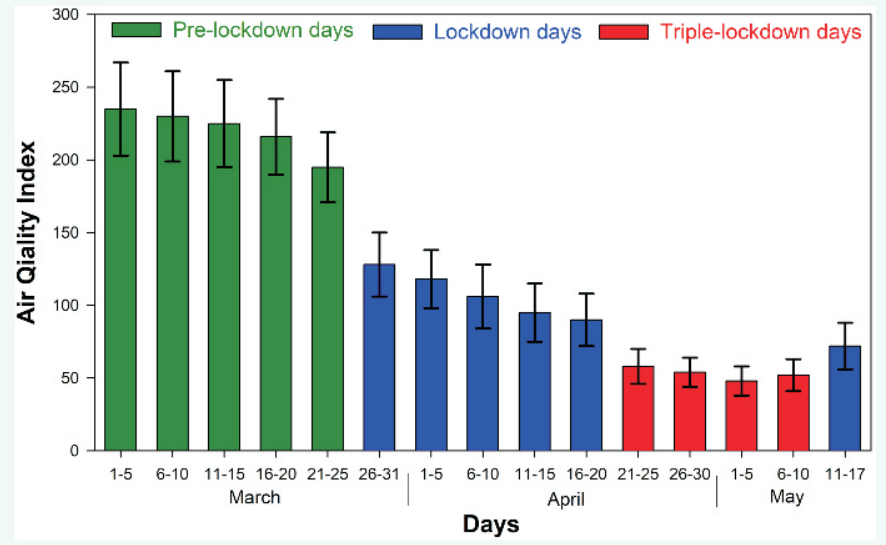

Figure-8: During triple-lockdown, the air quality improves.

In light of this, the current study aims to assess the effect of lockdown and unlock on AQ and investigate the relationship between climate factors (climatic data and atmospheric air pollutants), socioeconomic influences, and COVID-19 prevalence in Maharashtra, India.

\section{Conclusion:}

The lockdown seems to have improved AQ in these huge, heavily developed urban areas of India where United States embassies are situated, but the lockdown has endangered the lives of millions of Indians. Our findings show a significant reduction in airborne contaminants throughout lockdown, mainly in Delhi and Kolkata, which are considered to be among the most polluted cities in India and the globe. The findings would prompt the Indian government to consider ways to strictly reduce motor vehicles and factory emissions to increase $\mathrm{AQ}$ and maintain improved community welfare in India.

Because of the COVID-19 pandemic, anthropogenic practices have slowed somewhat, increasing in the atmosphere, as shown by a substantial reduction in air quality and excessive noise after mid-March 2020. The COVID-19 pandemic had a strong impact on the transportation and manufacturing sectors, resulting in decreased operation. Newer technology, such as GIS and web-based channels, has effectively raised consciousness among the general public, causing them to be more concerned with environmental problems due to increased emissions (Kota et al., 2018). The current circumstances offered the first time in the modern world a scenario in which improvements in environmental factors could be measured in such a deadlock scenario, including their beneficial impact on the climate.

According to this report, after the COVID-19 induced lockout, there was a significant change in real and expected 
AQ in India. Extremely $60 \%$ of participants thought air quality had improved, and measured AQ had improved by $40 \%$ across the nation. Even without the influence of the media, the respondents expected an increase in AQ. Three independent areas were studied for the reduction of air emissions. The reduction in motorvehicle load has resulted in significant reductions in Nitrogen oxide levels in major tracked zones throughout the region. Likewise, $\mathrm{So}_{2}$ levels in manufacturing belts and coal mines were found to be significantly lower. The established connection matrix revealed a strong link between the contaminants and their potential sources. During the lockdown, there was an uptick in photochemical reactions, which resulted in a spike in ozone levels in several places. The respondents saw significant changes in vision, indoor $\mathrm{AQ}$, and fitness in addition to improved AQ. The drop of particulates influenced people's perceptions of improved AQ[30]. The chances ratio revealed a close relationship between experience and real AQ. This report also has community recommendations for improving AQ after the COVID-19 lockout is lifted.

\section{References:}

Dantas, G., Siciliano, B., França, B., da Silva, C. M. \& Arbilla, G. (2020): The impact of COVID-19 partial lockdown on the air quality of the city of Rio de Janeiro. Brazil Sci. Total Environ., 729:139085.

Dutheil, F., Baker, S.J. \& Navel, V. (2020): COVID-19 as a factor influencing air pollution? Environ. Pollut., 263(PtA):114466.

Franco, J.F., Pacheco, J., Behrentz, E. \& Belalcázar, L.C. (2015): Characterization and source identification of VOC species in Bogotá, Colombia. Atmósfera, 28(1):1-11.

Fuentes, J.D., Lerdau, M., Atkinson, R., Baidocchi, D., Bottenheim, J.W., Ciccioli, P., Lamb, B., Geron, C., Go, L. \& Guenther, A. (200o): Biogenic hydrocarbons in the atmospheric boundary layer: a review. Bull. Am. Meteorol. Soc., 81:1537-1575.

Garaga, R., Sahu, S.K. \& Kota, S.H. (2018): A review of air quality modeling studies in India: local and regional scale. Curr. Pollut. Rep., 4:59-73.

Gautam, S. \& Hens, L. (2020): SARS-CoV-2 pandemic in India: what might we expect? Environ. Dev. Sustain., 22(5):38673869.

Gautam, S. (2020): The influence of COVID-19 on air quality in India: a boon or inutile. Bull. Environ. Contam. Toxicol., 104(6):724-726.

Guo, H., Kota, S.H., Sahu, S.K. \& Zhang, H. (2019): Contributions of local and regional sources to PM2.5 and its health effects in north India. Atmos. Environ., 214:116867.

Guo, H., Kota, S.H., Sahu, S.K., Hu, J., Ying, Q., Gao, A. \& Zhang, H. (2017): Source apportionment of $\mathrm{PM}_{2.5}$ in North India using source-oriented airquality models. Environ. Poll., 231:426-436.

Kambalagere, Y. (2020): A Study on Air Quality Index (AQI) of Bengaluru, Karnataka during Lockdown Period to Combat Coronavirus Disease (Covid-19): Air quality turns 'better' from 'hazardous'. Stud. Indian Place Names, 40(69): 2394-3114.
Kotaa, S.H., Guoa, H., Myllyvirtad, L., Hub, J., Sahuc, S.K., Garagac, R., Yingb, Q., Gaof, A., Dahiyah, S., Wangi, Y., Zhanga, H. (2018): Year-long simulation of gaseous and particulate air pollutants in India. Atmos. Environ., 180:244-255.

Li, L., Li, Q., Huang, L., Wang, Q., Zhu, A., Xu, J., Liu, Z., Li, H., Shi, L., Li, R., Azari, M., Wang, Y., Zhang, X., Liu, Z., Zhu, Y., Zhang, K., Xue, S., Ooi, M. C. G., Zhang, D., \& Chan, A. (2020): Air quality changes during the COVID-19 lockdown over the Yangtze River Delta Region: An insight into the impact of human activity pattern changes on air pollution variation. Sci. Total Environ., 732:139282.

Mahato, S., Pal, S., \& Ghosh, K. G. (2020): Effect of lockdown amid COVID-19 pandemic on air quality of the megacity Delhi, India. Sci. Total Environ., 730:139086.

Monserrate, M. A., Ruano, M. A. \& Alcalde, L. S. (2020): Indirect effects of COVID-19 on the environment. Sci. Total Environ., 728:138813.

Mukherjee, M. \& Agrawal, A. (2018): Air pollutant levels are 12 times higher than guidelines in Varanasi, India. Sources and transfer. Environ. Chem. Lett., 16:1009-1016.

Nie, D., Shen, F., Wang, J., Ma, X., Li, Z., Ge, P., Ou, Y., Jiang, Y., Chen, M., Chen, M., Wang, T., \& Ge, X. (2021): Changes of air quality and its associated health and economic burden in 31 provincial capital cities in China during COVID-19 pandemic. Atmos. Res., 249:105328.

Otmani, A., Benchrif, A., Tahri, M., Bounakhla, M., Chakir, E. M., Bouch, M. E. \& Krombi, M. (2020): Impact of COVID-19 lockdown on $\mathrm{PM} 10, \mathrm{SO}_{2}$ and $\mathrm{NO}_{2}$ concentrations in Salé City (Morocco). Sci. Total Environ., 735:139541.

Parker, H. A., Hasheminassab, S., Crounse, J. D., Roehl, C. M., \& Wennberg, P. O. (2020): Impacts of Traffic Reductions Associated With COVID-19 on Southern California Air Quality.Geophys. Res. Lett., 47(23):1-9.

Sarella, G. \& Khambete, A. K. (2015): Ambient air quality analysis using air quality index-A case study of Vapi. Int. J. Innov. Res. Sci. Technol., 1(10):2349-6o10.

Selvam, S., Muthukumar, P., Venkatramanan, S., Roy, P.D., Bharath, K. M. \& Jesuraja, K. (2020): SARS-CoV-2 pandemic lockdown: Effects on air quality in the industrialized Gujarat state of India.Sci. Total Environ., 737:140391.

Sharma, S., Zhang, M., Gao, A., Zhang, H. \& Kota, S. H. (2020): Effect of restricted emissions during COVID-19 on air quality in India. Sci. Total Environ., 728:138878.

Siciliano, B., Carvalho, G., da Silva, C. M. \& Arbilla, G. (2020): The impact of COVID-19 partial lockdown on primary pollutant concentrations in the atmosphere of Rio de Janeiro and São Paulo Megacities (Brazil). Bull. Environ. Contam. Toxicol., 105:2-8.

Thorpe, A. J. \& Harrison, R. M. (2020): Sources and properties of non-exhaust particulate matter from road traffic: A review. Sci. Total Environ., 400:270-282.

Tobías, A., Carnerero, C., Reche, C., Massagué, J., Via, M., Minguillón, M. C., Alastuey, A., \& Querol, X. (2020): Changes in air quality during the lockdown in Barcelona (Spain) one month into the SARS-CoV-2 epidemic. Sci. Total Environ., 726:138540. 